\title{
Les silences de Pie XII, histoire d'une controverse.
}

\section{4-2002}

Doctorat d'histoire, sous la direction de Denis Pelletier à l'École pratique des hautes études (EPHE), soutenu le 13 décembre 2011.

\section{Muriel Guittat-Naudin}

\section{(2) OpenEdition} Journals

Édition électronique

URL : http://journals.openedition.org/assr/24585

DOI : $10.4000 /$ assr.24585

ISSN : $1777-5825$

Éditeur

Éditions de l'EHESS

Édition imprimée

Date de publication : 30 décembre 2012

Pagination : 309-358

ISSN : 0335-5985

Référence électronique

Muriel Guittat-Naudin, «Les silences de Pie XII, histoire d'une controverse. 1944-2002 », Archives de sciences sociales des religions [En ligne], 160 | octobre-décembre 2012, mis en ligne le 14 mars 2013, consulté le 19 avril 2019. URL : http://journals.openedition.org/assr/24585

Ce document a été généré automatiquement le 19 avril 2019

(c) Archives de sciences sociales des religions 


\title{
Les silences de Pie XII, histoire d'une controverse. 1944-2002
}

\author{
Doctorat d'histoire, sous la direction de Denis Pelletier à l'École pratique \\ des hautes études (EPHE), soutenu le 13 décembre 2011.
}

\section{Muriel Guittat-Naudin}

1 Aujourd'hui, il est généralement admis dans l'opinion publique que le pape Pie XII a assisté sans rien dire et sans rien faire au massacre des Juifs européens. Cette opinion est le plus souvent assortie d'un jugement moral : au tribunal de l'histoire, Eugenio Pacelli est déclaré coupable de s'être tu. Mais tel ne fut pas toujours le cas. À la Libération, le souverain pontife est admiré pour la prudence avec laquelle il avait présidé aux destinées de l'Église pendant la guerre. Il est également loué pour son action charitable et pour l'œuvre de paix qu'il avait accomplie pendant le conflit. Il était aussi porté à son crédit un renforcement du prestige de l'institution pontificale. En soixante ans, l'homme de paix s'est donc définitivement effacé devant le pape du silence et aux éloges quasi unanimes ont succédé des condamnations tout aussi unanimes.

2 C'est à ce renversement radical de perspective mémorielle que ce doctorat est consacré. Il s'agit de comprendre comment une représentation dominante aujourd'hui, celle d'un pape silencieux face à la mort de six millions de Juifs, s'est construite progressivement depuis la fin de la guerre : la mémoire commune retient en effet désormais uniquement les non-dits de Pacelli devant le génocide alors qu'à la fin de la guerre elle les occultait largement. Ce travail vise également à expliquer pourquoi cette question suscite des polémiques incessantes dans l'espace public en mettant en lumière les ressorts des controverses.

3 En se fondant sur le dépouillement d'un vaste corpus de sources françaises essentiellement imprimées, cette thèse présente tout d'abord un récit raisonné des controverses entourant les silences de Pie XII qui met en évidence les périodes d'amnésie et de résurgence de la question du silence du pape. À la Libération, l'opinion commune juge que le Saint-Siège a respecté les missions traditionnelles de l'Église en temps de guerre - en particulier favoriser la paix et soulager les souffrances des victimes 
innocentes, qu'elles soient juives ou non. La version répandue insiste aussi sur l'impartialité du Saint-Siège pendant la guerre, impartialité qui contraste avec les initiatives jugées intempestives de Benoît XV pendant la Première Guerre mondiale : en France comme en Allemagne, son initiative de 1917 en faveur d'une paix blanche n'avait guère été appréciée. De toute évidence, le Saint-Père a incontestablement renforcé le prestige de l'institution pontificale. Si la plupart des contemporains estiment que le souverain pontife a parfaitement manœuvré la barque de Saint-Pierre dans les tumultes de la guerre, de rares intellectuels, souvent catholiques, considèrent néanmoins que la réserve de Rome n'allait pas de soi et qu'elle a pu conduire l'Église à se taire sur l'essentiel, l'obligation absolue de défendre la dignité et la liberté de l'homme. Un débat s'engage donc précocement sur les silences de la papauté. À de rares exceptions, en effet, les reproches ne portent pas sur l'absence de condamnation de l'extermination des Juifs par Pie XII, mais ils visent les non-dits du Vatican devant les atteintes innombrables aux droits de la personne, en particulier en Pologne où les catholiques ont été persécutés dès le début du conflit par les nazis et en Croatie où Ante Pavelitch, tout en se réclamant du catholicisme, a massacré Serbes orthodoxes et Juifs sans que le pape ne lance d'anathème.

4 Émanant d'intellectuels souvent catholiques ou communistes, des réserves s'expriment pourtant sur ses choix pendant la guerre, souvent en privé pour les premiers, et sur le mode polémique pour les seconds. Pourtant, assez rapidement, ce débat est étouffé par le contexte mémoriel et politico-religieux de la fin des années 1940-1950. Dans la mesure où le génocide juif est pour diverses raisons occulté par la mémoire de la résistance et de la déportation, rares sont ceux qui évoquent l'extermination des Juifs, et plus rares encore sont ceux qui s'intéressent au rôle de la papauté face au génocide. La guerre froide enterre définitivement la question des non-dits d'Eugenio Pacelli dans la mesure où les silences du Vatican pendant la guerre à l'égard de l'Allemagne nazie sont utilisés par Moscou pour dénoncer la partialité du Saint-Siège durant le conflit en raison des tendances présumées fascisantes et autoritaires de l'Église catholique. Contraints de resserrer les rangs pour faire face aux attaques, les fidèles n'osent guère exprimer de critiques à l'égard du Saint-Père. Toute évaluation sereine des choix de la papauté durant la guerre est dès lors impossible.

En 1963, cette "mémoire dominante" d'un pontife unanimement respecté se brise définitivement sur Le Vicaire. En s'attaquant à une personnalité dont le bilan et la personnalité avaient nourri un flot de commentaires élogieux quasi unanimes lors de sa mort quatre ans plus tôt, ce drame suscite un scandale mondial. Si Rolf Hochhuth n'est pas le premier à dénoncer ouvertement le silence de Pie XII, l'écho rencontré par cette pièce contribue à révéler une question jusque-là ignorée ou niée alors que la mémoire du génocide ressurgit à la faveur notamment du procès Eichmann: la "mémoire minoritaire » des silences de la papauté, longtemps sujette au refoulement, souvent cantonnée à la discussion privée pendant les années 1950, envahit alors l'espace public. Véritable séisme dramatique, historique et moral, Le Vicaire joue donc un rôle essentiel dans le retournement de l'opinion publique à l'égard de Pie XII ${ }^{1}$ en faisant voler en éclat les représentations d'un pape de la paix et de la charité et en révélant les manquements ou les défaillances de la hiérarchie catholique pendant la guerre. La pièce est d'ailleurs souvent perçue comme une œuvre roborative et salutaire qui décape de sa gangue hagiographique un passé trop lisse. À cet égard, il y a incontestablement un avant et après Le Vicaire. Depuis Le Vicaire, il est en effet généralement admis que le souverain 
pontife a assisté sans rien dire et sans rien faire à la destruction des Juifs européens. Le souverain pontife est désormais unanimement condamné pour ses silences.

6 Si le scandale est immense, c'est aussi que derrière les débats se dissimulent des motifs moins avouables: le problème de l'attitude de la papauté permet souvent en effet d'exprimer son opposition ou au contraire son soutien aux décisions conciliaires. Car la question du silence du pape, et donc de ses choix politiques pendant la Seconde Guerre mondiale, révèle une conception particulière de l'Église apostolique et romaine et de son chef qui semble profondément remise en cause par les premières décisions de Vatican II : le souverain pontife n'est plus seulement considéré comme le berger et le chef des catholiques, il s'adresse désormais à « tous les hommes de bonne volonté » et se pose en défenseur de l'humanité souffrante. Elle reflète également la manière dont l'Église concevait ses relations avec l'autre, en particulier le judaïsme. Là encore, le désaveu paraît manifeste: en dépit de ses faiblesses, la déclaration Nostra Aetate marque un tournant majeur dans l'histoire des relations judéo-chrétiennes.

7 Sur ces controverses ecclésiologiques et théologiques se greffe un dernier débat, le volet historique des discussions. Les historiens, amateurs ou professionnels, entrent alors en scène, bien souvent non pour présenter une vision cohérente et argumentée du passé, fondée sur la consultation et le croisement de sources, mais pour confirmer ou infirmer les assertions de Rolf Hochhuth ${ }^{2}$. À charge ou à décharge. La plupart des travaux confirment néanmoins la principale accusation du dramaturge allemand selon laquelle le souverain pontife a effectivement fait le choix du silence pendant la guerre et nuancent les raisons invoquées par Hochhuth pour expliquer ce non-dit. La publication des onze volumes des Actes et documents du Saint-Siège relatifs à la Seconde Guerre mondiale (1965-1981) dont l'initiative revient à Paul VI permet de valider ou d'infirmer les hypothèses émises par la première génération d'historiens des silences de la papauté.

8 Le détour par l'histoire ne fait donc pas taire les passions. Un temps mise en sourdine durant les années 1970, la question des silences du pape fait une réapparition remarquée dans l'espace public au milieu des années 1980 avant de devenir omniprésente dans la décennie suivante. Cette dernière période s'organise également autour de trois moments : le premier est caractérisé par la résurgence du problème de l'attitude de la papauté à l'égard des Juifs à la faveur d'une série d'accrocs dans les relations judéo-chrétiennes: l'affaire du Carmel d'Auschwitz, la réception de Kurt Waldheim au Vatican le 25 juin 1987 et la béatification contestée d'Edith Stein le $1^{\mathrm{er}}$ mai 1987 en sont les incidents les plus marquants.

Les années 1990-2000 se caractérisent par un rejeu notable des controverses en raison de la publication de nombreux ouvrages historiques ou polémiques ${ }^{3}$ et de l'adaptation cinématographique du Vicaire par Costa-Gavras en 2002, sous le titre Amen. Alors que le devoir de morale se mue en injonction éthique de plus en plus pressante, les débats révèlent que comme dans un certain nombre de questions historiques traitant de la Seconde Guerre mondiale, l'instrumentalisation du passé et le poids de la mémoire du génocide se conjuguent pour fixer le passé dans des images parfois sclérosées et obsédantes, en l'occurrence celle d'un pape de la Shoah dont la faillite morale est patente.

10 Récurrentes dans l'espace public, les polémiques autour des silences de Pie XII n'épargnent pas l'Église. Alors que le long cheminement de la mémoire de la Shoah dans les consciences catholiques et ecclésiales a conduit Jean-Paul II à s'engager sur la voie de la repentance, cette inflexion majeure voulue par le pape suscite des réticences, des interrogations, des doutes et parfois des contestations, voilées ou ouvertes. Le dernier 
volet de cette étude s'attache à montrer combien les débats autour des silences du pape renvoient à la manière dont les catholiques envisagent l'avenir du catholicisme.

11 Au-delà du récit des polémiques entourant la question des silences de Pie XII, ce travail permet donc d'analyser trois histoires : l'histoire de la mémoire de la destruction des Juifs d'Europe, l'histoire de la perception de la papauté comme autorité morale et universelle par l'opinion publique ; l'histoire enfin des enjeux proprement religieux des polémiques où se croisent des débats d'ordre théologique, ecclésiologique et pastoral, en particulier dans la manière dont l'Église construit et conçoit son rapport au judaïsme et son rapport au monde.

\section{NOTES}

1. Rolf Hochhuth, Le Vicaire, Paris, Le Seuil, 1963. Réédition en 2002.

2. Cf. Saul Friedländer, Pie XII et le III Reich. Documents, Paris, Le Seuil, 1964, 235 p. ; Jacques Nobécourt, Le Vicaire et l'histoire, Paris, Le Seuil, 1964, 381 p. ; Carlo Falconi, Le silence de Pie XII, Monaco, Éditions du Rocher, 1965, 397 p.; Guenter Lewy, L'Église catholique et l'Allemagne nazie, Paris, Stock, 1965, 358 p. ; Pinchas Lapide, Rome et les juifs, Paris, Le Seuil, 1967, 429 p. ; Jeno Levai, L'Église ne s'est pas tue : le dossier hongrois. 1940-1945, Paris, Le Seuil 1966, 141 p.

3. Cf. Annie Lacroix-Riz, Le Vatican, l'Europe et le Reich, Paris, Armand Colin, 1996, 539 p.; Pierre Blet, Pie XII et la Seconde Guerre mondiale d'après les archives du Vatican, Paris, Perrin, 1997, 336 p. ; John Cornwell, Le pape et Hitler. L'histoire secrète de Pie XII, Paris, Albin Michel, 1999, 496 p ; Georges Passelecq, Bernard Suchecky, L'encyclique cachée de Pie XI, Paris, La Découverte, 1995, 320 p.

\section{AUTEUR}

\section{MURIEL GUITTAT-NAUDIN}

Muriel.naudin@laposte.net 